\title{
ОБЗОРЫ
}

\section{Современное состояние и перспективы развития исследований в области управления оборотным капиталом компании}

\author{
Волков Д.Л. ${ }^{15}$, Никулин Е.Д.
}

Статья посвящена анализу современного состояния и перспектив развития исследований финансовых аспектов управления оборотным капиталом компании. На основе различий в управляемом объекте предложена оригинальная классификация уровней управления оборотным капиталом компании. Выделены три основных уровня управления оборотным капиталом: уровень элементов оборотного капитала, корпоративный уровень $u$ уровень ичепи поставок. По тематике, соответствующей каждому из рассматриваемых уровней управления, представлен краткий обзор основных научных работ, описаны полученные в них результаты и перечислены наиболее актуальные на сегоднямний день задачи.

\section{JEL: G32}

Ключевые слова: управление оборотным капиталом, запасы, дебиторская задолженность, финансовый цикл, рентабельность.

\section{Введение}

В центре внимания настоящей работы находятся наиболее важные с теоретической и практической точек зрения финансовые аспекты управления оборотным капиталом компании. Учитывая принципиальную важность решения вопросов, связанных с управлением оборотным капиталом, для любой компании, вполне закономерно то, что данная область менеджмента явилась предметом серьезного изучения на протяжении как минимум последних 70 лет. Исследователи анализировали различные аспекты указанной управленческой деятельности. Разработка и анализ многочисленных моделей управления оборотным капиталом компании привели к двум противоположным результатам. С одной стороны, данная область менеджмента была изучена многосторонне, что, очевидно, имеет как научную, так и практическую ценность. С другой стороны, управление оборотным капиталом превратилось во фрагментированную область знания, характеризующуюся отсутствием единого понимания актуальных исследовательских задач.

Целью настоящей статьи являются анализ и систематизация основных исследовательских направлений в области управления оборотным капиталом, существующих в настоящее время, а также конкретизация наиболее актуальных и практически значимых вопросов, которые могут стать предметом изучения в последующих научных работах.

Статья построена следующим образом. Вначале дается общая характеристика управления оборотным капиталом компании как области научных исследований и приводится оригинальная классификация уровней управления оборотным капиталом. Далее конкретизируются основные направления исследований, соответствующие каждому из

\footnotetext{
15 Д-р эконом. наук, профессор финансов PricewaterhouseCoopers, профессор кафедры финансов и учета Высшей школы менеджмента Санкт-Петербургского государственного университета.

16 Канд. эконом. наук, ассистент кафедры финансов и учета Высшей школы менеджмента СанктПетербургского государственного университета.
} 
выделенных уровней управления, с перечислением основных достигнутых результатов по каждому из них. Для каждого уровня управления оборотным капиталом отмечаются актуальные и практически значимые задачи, которые могут составить основу для последующих исследований в этой области.

\section{1. Управление оборотным капиталом как область исследований}

Под управлением оборотным капиталом в настоящей работе понимается изменение величины и структуры оборотного капитала в соответствии с определенными целями. Основной целью управления оборотным капиталом является обеспечение баланса между рентабельностью и ликвидностью компании (Brealey, Myers, Allen, 2008; Ковалев, 2002; Ковалев, 2008). Иными словами, объем оборотных активов должен быть достаточным для погашения обязательств компании (хотя бы в краткосрочной перспективе), но в то же самое время оборотные активы должны обеспечивать компании достижение требуемой нормы рентабельности, поэтому излишние инвестиции в эти активы невыгодны (Ricci, 2000; Eljelly, 2004).

В общем случае можно констатировать, что управление оборотным капиталом компании осуществляется на трех уровнях, характеризующихся различием в объектах управления:

1) уровень элементов оборотного капитала;

2) корпоративный уровень;

3) уровень цепи поставок.

На уровне элементов оборотного капитала в качестве объекта управления используются отдельные элементы оборотного капитала компании (запасы, дебиторская задолженность, кредиторская задолженность, денежные средства и др.). Авторы соответствующих работ исследуют факторы, влияющие на объем того или иного вида оборотных активов или краткосрочных обязательств, не учитывая, как правило, взаимосвязи, которые существуют между элементами оборотного капитала.

На корпоративном уровне анализа акцент смещается с отдельных элементов оборотного капитала на совокупные результаты управления этим объектом. Особую роль на этом уровне играют интегральные показатели управления оборотным капиталом - прежде всего показатели операционного и финансового циклов фирмы. Основное внимание в проводимых исследованиях уделяется взаимосвязи указанных интегральных показателей и результатов деятельности фирмы (рентабельности активов, добавленной ценности и т.д.).

На уровне цепи поставок приоритетным является управление оборотным капиталом уже не отдельной компании, а всей цепи поставок, к которой принадлежит фирма (т.е. совокупности компаний). Основная идея, лежащая в основе проводимых на данном уровне исследований, заключается в том, что улучшение процесса управления оборотным капиталом отдельной компании в определенных случаях может принести ей лишь краткосрочные экономические выгоды, которые будут нивелированы в будущем ухудшением позиций ее партнеров. Поэтому необходимо проводить совокупный анализ управления оборотным капиталом всех компаний, включенных в цепь поставок.

Далее рассмотрим подробнее основные направления исследований в области управления оборотным капиталом, соответствующие каждому из трех уровней управления.

\section{2. Исследования в области управления оборотным капиталом на уровне элементов оборотного капитала}

На данном уровне исследователями рассматриваются способы управления отдельными элементами оборотного капитала компании. Соответственно, можно выделить основные направления исследований, соответствующие важнейшим элементам оборотного капитала прежде всего запасам, денежным средствам и дебиторской задолженности. 
Управление запасами (inventory management)

Как уже отмечалось в работе, одна из основных задач управления оборотным капиталом содержательно сводится к определению объема инвестиций в оборотные активы. В данном конкретном случае перед компанией возникает задача оптимизации своих инвестиций в материально-производственные запасы.

Решение данной задачи формализуется в рамках ряда математических моделей, описанных в литературе, среди которых наибольшее распространение получила модель оптимальной партии заказа Вильсона (Wilson, 1934). Результатом использования данной модели является вычисление оптимального размера заказа, минимизирующего затраты организации, связанные с запасами.

Относительная легкость определения искомой величины - оптимальной партии заказа - в соответствии с моделью Вильсона связана прежде всего с тем, что данная модель базируется на ряде существенных допущений. К их числу относятся следующие: применение модели только для одного вида товара, постоянный уровень спроса в течение планового периода времени и т.д. (Knight, 1972; Щиборщ, 2001; Семенова, Стерлигова, 2005).

Очевидно, что наличие в модели Вильсона отмеченных допущений существенно отдаляло ее от реальной практики бизнеса. По этой причине неудивительно, что дальнейшее развитие данной модели проходило по пути снятия или смягчения одного или нескольких из этих допущений. Так, например, X. Вейсс предложил модель, которая, с его точки зрения, более корректно определяла затраты фирмы, связанные с запасами. В этой модели затраты на хранение запасов определялись как находящиеся в нелинейной функциональной зависимости от времени хранения объекта (Weiss, 1982). Дж. Бузакоттом в 1975 году была предложена модель, учитывающая фактор инфляции (Buzacott, 1975). Попытки совершенствования модели Вильсона производились и отечественными специалистами. В частности, А.И. Шукаев в рамках разрабатываемой им модели (Шукаев, 2005) предлагает при определении оптимального размера заказа ориентироваться на затраты, связанные с приобретением единицы материала.

Очевидно, что развитие исследований в области управления запасами может продолжаться по линии поиска более точного решения оптимизационных задач, связанных с затратами компании, касающихся инвестиций в запасы. Важно учитывать в моделях различные факторы, влияющие на инвестиции компании в запасы, среди которых немаловажную роль играет отраслевая специфика компаний.

\section{Управление денежными средствами (cash management)}

За последние 60 лет неоднократно предпринимались попытки сформулировать и обосновать мотивы, заставляющие компании хранить денежные средства, и выделить факторы, влияющие на объем денежных средств компаний.

В первых работах по данному направлению объем денежных средств компании определялся в соответствии с трансакционными издержками, связанными с данным активом (Baumol, 1952; Miller, Orr, 1966). В дальнейшем в рассмотрение вовлекались и другие факторы и мотивы, определявшие величину денежных средств компании. Так, еще одним побудительным мотивом хранить денежные средства для компаний является мотив предосторожности. Исследования (Kim, Mauer, Sherman, 1998; Opler, Pinkowitz, Stulz, Williamson, 1999; Almeida, Campello, Weisbach, 2004) показывают, что компании, характеризующиеся более высокой неопределенностью денежных потоков, хранят больший запас денежных средств.

Существенным фактором, влияющим на доступ компаний к внешнему финансированию, является размер компании. Поэтому он должен определять в числе прочего и величину хранимых денежных средств. В исследовании К. Маллиган (Mulligan, 
1997) на выборке из 12000 компаний более чем за тридцатилетний период времени (19611992) эмпирически подтверждается гипотеза о том, что крупные компании хранят меньший объем денежных средств в процентах к объему продаж, чем компании меньшего размера.

Отдельного внимания заслуживают исследования, подвергающие эмпирическому тестированию целый комплекс теорий, объясняющих объем денежных средств компаний. К такого рода исследованиям следует, в частности, отнести работы М. Феррейры и А. Вилелы, а также Т. Бэйтса, К. Каали и Р. Сталтца (Ferreira, Vilela, 2004; Bates, Kahle, Stulz, 2009). В работе М. Феррейры и А. Вилелы (Ferreira, Vilela, 2004) анализируется набор факторов, имевших влияние на объем денежных средств публичных компаний 12 стран Евросоюза за период с 1987 по 2000 год. В исследовании Т. Бэйтса, К. Каали и Р. Сталтца (Bates, Kahle, Stulz, 2009) объектом исследования являются компании США. Авторы изучают факторы, которые вызвали существенный рост остатка денежных средств американских компаний за период с 1980 по 2006 год.

Дальнейшее исследование факторов, влияющих на объем денежных средств компании, на различном эмпирическом материале, включая российские фирмы, представляется актуальной задачей. Так, например, в числе прочих можно рассмотреть практически важную задачу о влиянии последствий недавнего мирового финансового кризиса на остатки денежных средств российских компаний.

\section{Управление дебиторской задолженностью (receivables management)}

Современные исследования в области управления дебиторской задолженностью ведутся как минимум по двум основным направлениям.

Первое направление состоит в формализации и эмпирическом тестировании теорий, объясняющих, почему компании используют в своей деловой практике инструмент коммерческого кредитования. Использование инструмента коммерческого кредитования со стороны продавцов может, например, объясняться тем, что с его помощью компания имеет возможность простимулировать объем продаж, особенно в период падения спроса на ее продукцию (Emery, 1987). Со стороны покупателей, приобретение продукции в кредит может, в частности, объясняться трансакционным мотивом (возможностью заблаговременно планировать свои денежные потоки) (Ferris, 1981). Эмпирическое тестирование этих и других теорий коммерческого кредитования проводится в работах М. Делуфа и М. Йегерса, М. Питерсена и Р. Рэйена, Дж. Нисканена и М. Нисканена, Р. Бастоса и Х. Пиндадо (Deloof, Jegers, 1996; Petersen, Rajan, 1997; Niskanen, Niskanen, 2006; Bastos, Pindado, 2007).

Второе направление исследований в области управления дебиторской задолженностью компаний связано с изучением форм кредитных условий, используемых ими. Так, например, в исследовании Ч. Нга, Дж. Смит и Р. Смита (Ng, Smith, Smith, 1999), авторами анализируется, какие варианты кредитных политик могут существовать, и как это связано с отраслевыми особенностями компаний.

В качестве одного из путей дальнейшего развития исследований в области управления дебиторской задолженностью можно рассматривать анализ изменений кредитной политики компаний с течением времени. Важно также проследить тенденции, которые существуют в области использования инструмента коммерческого кредитования, на рынках развивающихся стран.

\section{3. Исследования в области управления оборотным капиталом на корпоративном уровне}

Особенность управления оборотным капиталом компании на корпоративном уровне состоит в том, что в данном случае оборотный капитал трактуется как целостный объект управления. Это означает, что внимание аналитика переключается с отдельных элементов оборотного капитала на текущую деятельность компании в целом. По этой причине в центре 
внимания оказываются финансовые показатели, оценивающие совокупные результаты управления оборотным капиталом, - например, показатель финансового цикла.

Можно выделить по меньшей мере два направления исследований, соответствующие рассматриваемому уровню управления оборотным капиталом компании.

Первое направление исследований предполагает анализ взаимосвязи совокупных результатов управления оборотным капиталом и экономических результатов компании в целом. За последние двадцать лет было проведено значительное число исследований, посвященных проблеме влияния величины финансового цикла на рентабельность компании (Kamath, 1989; Soenen, 1993; Jose, Lancaster, Stevens, 1996; Shin, Soenen, 1998; Deloof, 2003; Lazaridis, Tryfonidis, 2006; Padachi, 2006; Garcia-Teruel, Martinez-Solano, 2007; Zariyawati et al., 2009; Falope, Ajilore, 2009; Mathuva, 2010). Эти исследования были выполнены на материале различных страновых рынков - Бельгии, Греции, Испании, Кении, Маврикия, Малайзии, Нигерии, США. Важный результат проведенных исследований состоит в том, что, несмотря на существование определенной специфики, касающейся отдельных отраслей и периодов наблюдения, между рентабельностью активов компании и финансовым циклом существует обратная связь. Иными словами, с целью увеличения рентабельности активов и, соответственно, ценности, компании выгодно уменьшать свой финансовый цикл.

Второе направление исследований на данном уровне управления оборотным капиталом связано с изучением факторов, влияющих на выбор типа политики управления оборотным капиталом компании ${ }^{17}$. Этому посвящены многочисленные эмпирические работы (Lamberson, 1995; Chiou, Cheng, Wu, 2006; Narender, Menon, Shwetha, 2008; Nazir, Afza, 2009; Al Taleb, Al Zoued, Al Shubiri, 2010)). Указанные исследования были также выполнены на материале различных страновых рынков. Авторы анализировали влияние на объем оборотного капитала различных факторов - как внутренних, так и внешних по отношению к компании. Среди внутренних факторов значительное влияние на объем оборотного капитала оказывает, например, уровень финансового левериджа компании. Между этими переменными, согласно проведенным исследованиям, существует обратная связь. Анализируя же внешние факторы, исследователи, в частности, приходят к выводу о том, что уровень экономического развития страны существенно не меняет потребности в оборотном капитале компаний.

Проведение аналогичных исследований на материале российских компаний, безусловно, представляет научный и практический интерес.

\section{4. Исследования в области управления оборотным капиталом на уровне цепи поставок}

На данном уровне управления оборотным капиталом в центре внимания исследователей оказывается не отдельная компания, а вся цепь поставок, к которой она принадлежит. Соответственно, центральной проблемой становится совершенствование процессов управления оборотным капиталом во всей совокупности компаний-партнеров одновременно. Таким образом, исследования в области управления оборотным капиталом выводятся на новый, более высокий уровень обобщения.

В работе Э. Хофманна и Г. Котзаба (Hofmann, Kotzab, 2010) убедительно показано, что улучшение управления оборотным капиталом в рамках одной компании в определенных случаях может привести лишь к краткосрочному росту финансовых результатов этой фирмы. В будущем же компания может столкнуться со значительными трудностями в своей текущей деятельности по причине ухудшения финансового состояния своих поставщиков и покупателей. По этой причине компании-партнеры должны рассматриваться как единое целое с точки зрения управления оборотным капиталом и с точки зрения создаваемой

\footnotetext{
${ }^{17}$ В зависимости от предусматриваемого целевого объема оборотного капитала принято выделять три основных политики управления оборотным капиталом компании - осторожную (консервативную), умеренную и агрессивную (ограничительную) (Бригхем, Гапенски, 2004).
} 
ценности. Указанный подход приводит к возникновению ряда требующих теоретического осмысления вопросов, основным из которых является следующий - каким образом можно адекватно измерить результаты управления оборотным капиталом всех компаний, включенных в цепь поставок? Один из подходов к решению этого вопроса заключается в расчете показателя так называемого совокупного финансового цикла (collaborative cash-tocash cycle) цепи поставок и принятия на его основе управленческих решений в отношении отдельных компаний (Farris II, Hutchison, 2002; Hofmann, Kotzab, 2010).

Совокупный финансовый цикл может быть представлен как сумма финансовых циклов всех компаний, входящих в цепь поставок. Анализ этого показателя предполагает переход к расчету дневных издержек отдельных компаний, связанных с привлечением финансирования, которые вызываются изменением моментов оплаты между партнерами. Соответственно, ключевым фактором, определяющим совокупную ценность компанийпартнеров, становится средневзвешенная стоимость капитала компаний (WACC). В том случае, если WACC компании-покупателя меньше, чем WACC компании-поставщика, ради улучшения совокупных результатов покупателю может быть выгодно ускорить оплату своих счетов. В том случае, когда WACC компании-поставщика меньше, чем WACC компаниипокупателя, поставщику может быть целесообразно пойти на продление отсрочки оплаты счетов со стороны покупателя.

Безусловно, реализация такого подхода требует значительной подготовительной работы со стороны всех компаний, вовлеченных в партнерские отношения в рамках цепи поставок. Эта работа, в частности, предполагает проведение комплексного анализа финансового состояния партнеров (в особенности оборотного капитала); обсуждение преимуществ совместного управления финансовым циклом цепи поставок и непосредственно корректировку параметров расчетных отношений (Hutchison, Farris II, Fleischman, 2009).

Учитывая сказанное, дальнейшее развитие принципов и методов управления оборотным капиталом в цепях поставок с использованием разнообразных финансовых показателей представляется чрезвычайно важным. Необходимо, в частности, уточнить, при каких условиях и в каких отраслях их применение дает наибольший эффект, учитывая то, что компания может быть одновременно вовлечена в несколько цепей поставок.

\section{Заключение}

Настоящая работа посвящена систематизации основных исследовательских направлений, существующих в области управления оборотным капиталом компании. В статье определены три основных уровня управления оборотным капиталом: уровень элементов оборотного капитала компании, корпоративный уровень и уровень цепи поставок.

Сформулированная классификация уровней управления оборотным капиталом, по сути, отражает исторические закономерности развития подходов к управлению оборотным капиталом, которые в целом соответствуют принципу индукции, предполагающему выведение общего из частных суждений. С этой точки зрения, третий уровень управления, исследующий «комплексное» управление оборотным капиталом компаний, вовлеченных в цепи поставок, не только имеет дело с более сложным объектом управления, но и является наиболее значимым по сравнению с другими уровнями. Однако «комплексное» управление оборотным капиталом невозможно без понимания принципов управления элементами оборотного капитала отдельной компании. По этой причине представляется, что результаты исследований, соответствующих каждому из уровней управления оборотным капиталом, взаимно обогащают друг друга, предоставляя компаниям новые возможности совершенствования организации своих текущих операций, что является залогом роста долгосрочной ценности компании и улучшения благосостояния собственников. 


\section{Список литературы}

1. Бригхем Ю., Гапенски Л. Финансовый менеджмент: Полный курс: пер. с англ. СПб.: Экономическая школа, 2004.

2. Джалаев Т.К. Анализ дебиторской и кредиторской задолженности предприятия // Экономический анализ: теория и практика. 2005. № 7. С. 58-65.

3. Ковалев В.В. Финансовый анализ: методы и процедуры. М.: Финансы и статистика, 2002.

4. Ковалев В. В. Финансовый менеджмент: теория и практика. М.: Проспект, 2008.

5. Крейнина М.Н. Управление движением дебиторской и кредиторской задолженности предприятия // Финансовый менеджмент. 2001. № 3. С. 25-28.

6. Семенова И., Стерлигова А. Оптимальный размер заказа или загадочная формула Вильсона // Логистик \& система. 2005. № 2. С. 64-69.

7. Шукаев А.И. Модели планирования закупок материальных ресурсов // Менеджмент в России и за рубежом. 2005. № 3. С. 84-90.

8. Щиборщ К.В. Управление запасами на промышленном предприятии // Финансовый менеджмент. 2001. № 5. С. 28-36.

9. Almeida, H., Campello, M., Weisbach, M.S. (2004), The Cash Flow Sensitivity of Cash, Journal of Finance, 59(4) (2004) 1777-1804.

10. Al Taleb, G., Al Zoued, A., Al Shubiri, F. (2010), The Determinants of Effective Working Capital Management Policy: A Case Study on Jordan, Interdisciplinary Journal of Contemporary Research in Business, 2(4) (2010) 248-264.

11. Bastos, R., Pindado, J. (2007), An Agency Model to Explain Trade Credit and Empirical Evidence, Applied Economics, 39 (2007) 2631-2642.

12. Bates, T.W., Kahle, K.M., Stulz, R.M. (2009), Why Do U.S. Firms Hold So Much More Cash Than They Used To?, Journal of Finance, LVIV(5) (2009) 1985-2021.

13. Baumol, W.J. (1952), The Transactions Demand for Cash: an Inventory Theoretic Approach, Quarterly Journal of Economics, 66 (1952) 545-556.

14. Brealey, R.A., Myers, S.C., Allen, F. (2008), Principles of Corporate Finance. NY: McGraw-Hill.

15. Buzacott, J. (1975), Economic Order Quantity with Inflation, Operations Research Quarterly, 26 (1975) 553-558.

16. Chiou, J., Cheng, L, Wu, H. (2006), The Determinants of Working Capital Management, Journal of American Academy of Business, 10(1) (2006) 149-155.

17. Deloof, M. (2003), Does Working Capital Management Affect Profitability of Belgian Firms?, Journal of Business, Finance and Accounting 30(3\&4) (2003) 573-587.

18. Deloof, M. Jegers, M. (1996), Trade Credit, Product quality and Intragroup Trade: Some European Evidence, Financial management, 25(3) (1996) 945-968.

19. Eljelly, A. (2004), Liquidity-Profitability Tradeoff: an Empirical Investigation on the Emerging Market, International Journal of Commerce and Management, 14(2) (2004) 4861.

20. Emery, G. (1987), An Optimal Financial Response to Variable Demand, Journal of Financial and Quantitative Analysis, 22(2) (1987) 209-225.

21. Falope, O., Ajilore, O. (2009), Working Capital Management and Corporate Profitability: Evidence from Panel Data Analysis of Selected Quoted Companies in Nigeria, Research Journal of Business Management, 3(3) (2009) 73-84.

22. Farris II, M.T., Hutchison, P.D. (2002), Cash-To-Cash: The New Supply Chain Management Metric, International Journal of Physical Distribution \& Logistics Management, 32(4) (2002) 288-299.

23. Ferreira, M.A., Vilela, A.S. (2004), Why Do Firms Hold Cash? Evidence from EMU countries, European Financial Management, 10(2) (2004) 295-319. 
24. Ferris, S.J. (1981), A transactions theory on trade credit use, Quarterly Journal of Economics, 94 (1981) 243-270.

25. Garcia-Teruel, P., Martinez-Solano, P. (2007), Effects of Working Capital Management on SME Profitability, International Journal of Managerial Finance, 3(2) (2007) 164-177.

26. Gitman, L. (1974), Corporate Liquidity Requirement: a Simplified Approach, The Financial Review, 9 (1974) 79-88.

27. Gosman, M., Kohlbeck, M. (2005), The Relationship Between Supply-Chain Economies and Large Retailers' Working Capital, Commercial Lending review, Jan-Feb (2005) 9-14.

28. Hofmann, E., Kotzab, H. (2010), A Supply Chain-Oriented Approach of Working Capital Management, Journal of Business Logistics, 31(2) (2010) 305-330.

29. Hutchison, P.D, Farris II, M.T., Fleischman, G.M. (2009), Supply Chain Cash-To-Cash: Strategy for the 21st century, Strategic Finance, July (2009) 41-48.

30. Jose, M., Lancaster, C., Stevens, J. (1996), Corporate Returns and Cash Conversion Cycles, Journal of Economics and Finance, 20(1) (1996) 33-46.

31. Kamath, R. (1989), How Useful are Common Liquidity Measures?, Journal of Cash Management, 9(1) (1989) 24-28.

32. Kim, C-S., Mauer, D.C., Sherman, A.E. (1998), The Determinants of Corporate Liquidity: Theory and Evidence, Journal of Financial and Quantitative Analysis, 33(3) (1998) 335359.

33. Knight, W. (1972), Working Capital Management: Satisficing versus Optimization, Financial Management, 1(1) (1972) 33-40.

34. Lamberson, M. (1995), Changes of Working Capital of Small Firms in relation to Changes in Economic Activity, 10(2) (1995) 45-50.

35. Lazaridis, I., Tryfonidis, D. (2006), Relationship between Working Capital Management and Profitability of Listed Companies in the Athens Stock Exchange, Journal of Financial Management and Analysis, 19(1) (2006) 26-35.

36. Mathuva, D. (2010), The Influence of Working Capital Components on Corporate Profitability: a Surveys on Kenyan Listed Firms, Research Journal of Business Management, 4(1) (2010) 1-11.

37. Maxwell, C., Gitman, L. Smith, S. (1998), Working Capital Management and FinancialService Consumption Preferences of US and Foreign Firms: a Comparison of 1979 and 1996 Preferences, Financial Practice and Education, 8(2) (1998) 46-52.

38. Miller, M.H., Orr, D. (1966), A Model of the Demand for Money by Firms, Quarterly Journal of Economics, 80(3) (1966) 413-435.

39. Mulligan, C.B. (1997), Scale Economies, the Value of Time, and the Demand for Money: Longitudinal Evidence from Firms, Journal of Political Economy, 105 (1997) 1061-1079.

40. Narender, V., Menon, S., Shwetha, V. (2008), Factors Determining Working Capital Management in Cement Industry, South Asian Journal of Management, 15(4) (2008) 64-78.

41. Nazir, M., Afza, T. (2009), Working Capital Requirements and the Determining Factors in Pakistan, The Icfai Journal of Applied Finance, 15(4) (2009) 28-38.

42. Ng, C., Smith, J., Smith, R. (1999), Evidence on the Determinants of Credit Terms Used in Interfirm Trade, Journal of Finance, LIV(3) (1999) 1109-1129.

43. Niskanen, J., Niskanen, M. (2006), The Determinants of Corporate Trade Credit Policies in a Bank-dominated Financial Environment: the Case of Finnish Small Firms, European Financial Management, 12(1) (2006) 81-102.

44. Opler, T., Pinkowitz, L., Stulz, R., Williamson, R. (1999), The Determinants and Implications of Corporate Cash Holdings, Journal of Financial Economics, 52(1) (1999) 346.

45. Padachi, K. (2006), Trends in Working Capital Management and Its Impact on Firms' Performance: An Analysis of Mauritian Small Manufacturing Firms, International Review of Business Research Papers, 2(2) (2006) 45-58.

46. Petersen, M., Rajan, R. (1997), Trade credit: theories and evidence, Review of Financial 
Studies, 10(3) (1997) 661-691.

47. Ricci, C. (2000), International Working Capital Practices in the UK, European Financial Management, 6(1) (2000) 69-84.

48. Richards, V., Laughlin, E. (1980), A Cash Conversion Cycle Approach to Liquidity Analysis, Financial Management, 9(1) (1980) 32-38.

49. Ross, S.A., Westerfield, R.W., Jordan, B.D. (2008), Essentials of Corporate Finance. NY: McGraw-Hill.

50. Shin, H., Soenen, L. (1998), Efficiency of Working Capital Management and Corporate Profitability, Financial Practice and Education, 8 (1998) 37-45.

51. Soenen, L. (1993), Cash Conversion Cycle and Corporate Profitability, Journal of Cash Management, 13(4) (1993) 53-57.

52. Weiss, H. (1982), Economic Order Quantity with Nonlinear Holding Costs, European Journal of Operations Research, 9(1) (1982) 56-60.

53. Wilson, R. (1934), A Scientific Routine for Stock Control, Harvard Business Review, 13 (1934) 116-128.

54. Zariyawati, M., Annuar, M., Taufiq, H., Abdul Rahim, A. (2009), Working Capital Management and Corporate Performance: case of Malaysia, Journal of Modern Accounting and Auditing, 5(11) (2009) 47-54. 